\title{
MAX WEBER, JOHN NEVILLE KEYNES E O METHODENSTREIT: DISPUTA E CONCILIAÇÃO METODÓLOGICA
}

\author{
Hélio Afonso de Aguilar Filho* \\ Luis Felipe Eick ${ }^{* *}$
}

\begin{abstract}
RESUMO: Em fins do século XIX e início do século XX, a economia caminhava para se tornar uma ciência autônoma em meio a uma controvérsia mais geral, na qual se opunham os defensores do método abstrato/dedutivo e os do método histórico/indutivo. Dentre as soluções propostas para conciliar as duas perspectivas, destacam-se a de Max Weber na Alemanha e a de John Neville Keynes na Inglaterra. O presente trabalho pretende analisar e contrapor o posicionamento e as soluções propostas pelos dois autores para essa disputa metodológica. A hipótese é que o ponto de vista tanto de Keynes quanto de Weber teria sancionado o rumo posterior das Ciências Econômicas, por admitir lugares separados embora complementares à história e à teoria econômica dentro do pensamento econômico.
\end{abstract}

Palavras-chaves: Max Weber; Neville Keynes; Methodenstreit; Ciências Sociais.

\section{INTRODUÇÃO}

A defesa metodológica que sancionou a teoria econômica ortodoxa do século XX foi consolidada após um longo período de discussões acadêmicas que redefiniram, estruturaram e legitimaram um novo entendimento de ciência. Dentro desse contexto, o período que engloba o final do século XIX e o início do século XX é representativo desse processo, uma vez que é marcado pelo conflito entre duas concepções científico-metodológicas antagônicas: de um lado, o método indutivohistórico (defendido pelos historicistas) e, do outro, o método dedutivo abstrato (representado pela nascente escola marginalista).

Nos países de língua alemã, o acirramento do conflito se deu através daquilo que ficou conhecido como "Batalha dos Métodos" (Methodenstreit). Essa eclodiu em 1883-1884 envolvendo os principais representantes da Escola Histórica Alemã e da Escola Austríaca. A disputa tornou-se pública a partir da publicação de Untersuchungen über die Methode der Sozialwissenchaft und der Politischen Ökonomie insbesondere, de Carl Menger, e da subsequente crítica de Gustav von Schmoller. O aspecto central da discussão não foi apenas a contraposição da concepção histórica à concepção teórica abstrata; representou, de modo mais abrangente, a busca da definição de um método e de um objeto de estudo para a Ciência Econômica, bem como do papel das demais Ciências Sociais na análise dos fenômenos econômicos.

No domínio acadêmico anglo-saxão, o ponto central da disputa se deu com a oposição ao caráter excessivamente abstrato da teoria econômica clássica, principalmente a de orientação ricardiana. Autores como W. Bagehot, T. E. Cliffe Leslie, J. K. Ingram, influenciados pela indução e pelo empirismo de Francis Bacon, realçaram a necessidade de embasar a Ciência Econômica mais em fatos do que em pressuposições a priori. O papel dos procedimentos dedutivos na construção de teorias foi substituído na obra desses autores pela indução e pelos estudos históricos comparativos. Apesar de terem falhado em seu objetivo de derivar uma teoria por intermédio do estudo de processos históricos, a crítica desses autores foi, de certo modo, reconhecida e incorporada ao pensamento econômico corrente da época.

Dentro do contexto mencionado, a análise dos posicionamentos de John Neville Keynes e Max Weber traz novas perspectivas para os conflitos, primeiramente pelo fato de ambos haverem elaborado importantes obras metodológicas (Gesammelte Aufsätze zur Wissenschaftslehre, de Max Weber, e The Scope and Method of Political Economy, de Keynes) que não podem ser separadas do contexto da

\footnotetext{
* Prof. Adjunto UFRGS.

***ós graduando UFRGS.
} 
Batalha dos Métodos. Em segundo lugar, pois essas obras permanecem até hoje como importantes referências para se pensar questões metodológicas que envolvem a Economia e as Ciências Sociais em geral. Por fim, seus posicionamentos tornam-se particularmente relevantes, principalmente quando consideradas as propostas de ambos acerca de uma concepção mais rigorosa da Ciência Econômica e da delimitação do campo de estudo desta em relação às demais Ciências Sociais.

$\mathrm{O}$ objetivo do presente trabalho consiste em analisar e contrapor o posicionamento e as soluções propostas por Max Weber e John Neville Keynes para essa disputa metodológica. A hipótese é que o ponto de vista tanto de Weber quanto de Keynes teria sancionado o rumo posterior da Ciência Econômica, por admitir lugares separados, embora complementares, à história e à teoria econômica dentro do pensamento econômico. É possível afirmar adicionalmente que o posicionamento metodológico desses autores teve papel concreto na resolução do impasse, e de modo mais indireto, na posterior divisão do trabalho acadêmico e na separação da Economia das outras Ciências Sociais, como pode ser constatado pelos autores que Keynes e Weber influenciaram diretamente.

Uma justificativa para o presente trabalho é que, no contexto atual de redefinição dos marcos tradicionais que sustentam a divisão dos campos do saber nas Ciências Sociais, torna-se importante revisar o posicionamento desses dois autores, cujas formulações serviram de fundamento para alguns de seus sucessores legitimarem essa divisão. Uma revisão dos principais textos metodológicos de Weber e N. Keynes pode, portanto, lançar nova luz e solução para resolver as disputas atuais.

O presente trabalho está dividido da seguinte forma. Além dessa introdução consta uma segunda seção na qual se discute as contribuições metodológicas de Weber, uma terceira onde se discute as concepções de Neville Keynes, uma quarta onde, a partir de pontos específicos, são contrapostas as ideias dos dois autores. Por fim, seguem as conclusões do trabalho.

\section{MAX WEBER E A METHODENSTREIT}

Apesar de ser atualmente reconhecido como sociólogo, Max Weber ocupou suas principais posições acadêmicas na área da Ciência Econômica (foi professor de teoria econômica nas universidades de Freiburg e Heidelberg), tendo inclusive considerado a si próprio como economista ${ }^{1}$. Suas credenciais acadêmicas conferem, portanto, uma maior relevância e uma nova perspectiva ao seu posicionamento na Batalha dos Métodos (Methodenstreit), uma vez que as questões metodológicas que envolviam a economia lhe interessavam diretamente.

Do estudo da obra de Weber é difícil definir qual o seu posicionamento em relação à disputa metodológica, por apresentar afinidades intelectuais com ambos os lados. De maneira simplificada, pode-se observar que, em termos da definição do objeto de estudo da Ciência Econômica, Weber encontrava-se mais próximo de Schmoller. Todavia, apesar de não ter se envolvido diretamente na Methodenstreit, Weber posicionou-se claramente contra Schmoller e a Escola Histórica na chamada Batalha dos Juízos de Valor (Werturteilstreit). Sendo assim, apesar da tentativa de alguns manuais de História do Pensamento Econômico ${ }^{2}$ de enquadrá-lo dentro da vertente histórica, seu posicionamento em termos metodológicos aproxima-se muito mais da concepção de Menger e da Escola Austríaca.

Um elemento que coloca Weber a lado dos austríacos e de Menger, particularmente, é o fato de estes lançarem mão do recurso do individualismo metodológico (ou método analítico-compositivo, como referido por Menger) como base para suas teorias sociais. Dessa forma, ambos partem da premissa de que os fenômenos sociais podem ser explicados a partir do comportamento individual. Embora a sociologia weberiana trate de fenômenos coletivos, esses devem ser entendidos como conjunto das ações de indivíduos relacionando-se reciprocamente. A Escola Histórica, por outro lado,

\footnotetext{
${ }^{1}$ Na obra "A Ciência como Vocação", Weber (2000, p, 1) afirma "É peculiar a nós, economistas, um certo pedantismo, ao qual gostaria de me ater".

${ }^{2}$ Os manuais de História do Pensamento Econômico de Hunt (2005) e Brue (2005), por exemplo.
} 
concentra sua análise predominantemente em categorias supraindividuais e institucionais. Para Schmoller, por exemplo, a sociedade é concebida como uma totalidade orgânica e natural, as instituições são produtos de entidades coletivas, dos costumes e das leis.

Fator fundamental para a concepção metodológica weberiana é a formulação dos tipos ideais. De acordo com a definição de Weber (2001, p.137-138), esses construtos são formados a partir de uma "acentuação unilateral de um ou vários pontos de vista", contribuindo para a formação de "um quadro homogêneo de pensamento". Em outras palavras, os tipos ideais consistem em um ordenamento analítico da realidade caótica que não têm nenhuma base empírica significativa. Menger (1985) também destaca a importância da classificação de tipos e relações típicas em Untersuchungen. Não obstante, de acordo com Feijó (2000, p. 21), "os austríacos nunca aderiram ao preceito metodológico de utilizar tipos ideais weberianos". Observa-se, de fato, que, apesar de fazer referências a tipos e relações típicas, Menger acentua o fato de estes basearem-se fundamentalmente em formas empíricas ${ }^{3}$, enquanto Weber (2001, p.140) faz questão de destacar o seu distanciamento da realidade concreta:

\begin{abstract}
Se quisermos tentar uma definição genética do conteúdo do conceito, restar-nos-á apenas a forma do tipo ideal, no sentido anteriormente estabelecido. Trata-se de um quadro de pensamento, não da realidade histórica, e muito menos da realidade "autêntica"; não serve de esquema em que se possa incluir a realidade à maneira de exemplar. Tem, antes, o significado de um conceito-limite, puramente ideal, em relação ao qual se mede a realidade a fim de esclarecer o conteúdo empírico de alguns dos seus elementos importantes, e com o qual esta é comparada.
\end{abstract}

Ainda que pesem algumas diferenças importantes nas concepções dos dois autores, pode-se afirmar, contudo, que a finalidade prática dos tipos idealizados por Menger e dos tipos ideais weberianos é a mesma, qual seja, a de ordenar a realidade para fins de construção teórica.

Uma das críticas de Menger à Escola Histórica é quanto à pretensão dos membros dessa em construir uma ciência da economia que não estabelecesse distinções entre suas disciplinas específicas. De acordo com Hayek (1992), Weber foi diretamente influenciado por essa concepção ${ }^{4}$. Uma particularidade da abordagem weberiana é que, apesar de defender a diferenciação disciplinar dentro da Ciência Econômica, essa procura estabelecer uma mediação entre a economia analítica e a economia histórica, entre a teoria e a empiria, ao dedicar grande parte de seus esforços acadêmicos a questões relacionadas à sociologia econômica.

Com relação à oposição entre método individualizante e generalizante, pode-se dizer que nem Menger nem Weber se opuseram à indução histórica, apenas afirmaram que essa não seria suficiente para fornecer uma explicação completa dos fenômenos econômicos, como afirmavam os historicistas. Já o método generalizante, seria um recurso indispensável para a construção de teorias sociais, por permitir estabelecer relações entre fenômenos distintos, bem como relações de causalidade legítimas (mesmo que a custo de um distanciamento da realidade). É importante ressaltar que Weber não busca, a partir do método generalizante, construir um sistema de leis. Isto é, Weber (2001, p.130) afirma que o "estabelecimento de regularidades não é a finalidade, mas um meio do conhecimento" e que o estabelecimento de leis "não é mais que uma questão de conveniência em cada caso concreto".

\footnotetext{
3 "In spite of the great variety of concrete phenomena, we are able, even with cursory observation, to perceive that not every single phenomenon exhibits a particular empirical form differing from that of all the others. Experience teaches us, rather, that definite phenomena are repeated, now with greater exactitude, now with lesser, and recur in the variation of things. We call these empirical forms types" (MENGER, 1985, p.36).

4 "Menger tinha um grande interesse por história e pela gênese das instituições, e estava ansioso principalmente por influenciar a diferença da natureza da tarefa da teoria e da tarefa da história propriamente dita e por prevenir a confusão entre seus métodos. A distinção, tal como ele a formulou, influenciou consideravelmente a obra posterior de Rickert e de Max Weber" (HAYEK, 1992).
} 
Ademais, é importante, segundo Weber, estabelecer uma diferenciação qualitativa do uso do método generalizante entre as ciências da natureza e as ciências da cultura, diminuindo sua importância para a compreensão de fenômenos históricos concretos:

\begin{abstract}
Para as ciências exatas da natureza, as leis são tanto mais importantes e valiosas quanto mais geral é a sua validade. Para o conhecimento das condições concretas dos fenômenos históricos, as leis mais gerais são frequentemente as menos valiosas, por serem as mais vazias de conteúdo. Isto porque, quanto mais vasto é o campo abrangido pela validade de um conceito genérico - isto é, quanto maior a sua extensão - tanto mais nos afasta da riqueza da realidade, posto que, para poder abranger o que existe de comum no maior número possível de fenômenos, forçosamente deve ser o mais abstrato e pobre de conteúdo (WEBER, 2001, p. 130).
\end{abstract}

Dando continuidade, Weber afirma que a finalidade de redução da realidade empírica a determinadas leis carece de justificativa em relação às Ciências Sociais não pelo fato de estas estarem supostamente menos sujeitas a leis, mas pelas razões seguintes:

\begin{abstract}
a) porque o conhecimento de leis sociais não é um conhecimento do socialmente real, mas unicamente um dos diversos meios auxiliares de que nosso pensamento se serve para esse efeito; e b) porque nenhum conhecimento dos acontecimentos culturais poderá ser concebido senão com base na significação que a realidade da vida, sempre configurada de modo individual, possui para nós em determinadas relações singulares (WEBER, 2001, p. 130).
\end{abstract}

Na condição de economista, Max Weber lançou mão de procedimentos matemáticos e dedutivos $^{5}$, o que não significa que ele percebesse superioridade do método dedutivo em relação ao indutivo. Na verdade, o autor era contrário a qualquer espécie de dogmatismo em relação ao método, sendo a função de um método fazer progredir o saber, e não ser fiel a um pretenso ideal de conhecimento. Weber defende, portanto, uma visão pluralista quanto ao método.

Na mesma linha, Menger (1985) irá criticar a concepção de que a economia política é uma ciência formalmente homogênea e o esforço resultante dessa concepção de idealizar um único método para a ciência. Dessa forma, esse também fez uma defesa da pluralidade metodológica, ao afirmar que não se deve tratar do método, mas "dos métodos", da economia política:

\begin{abstract}
Accordingly, we cannot speak of one method, the method of political economy, but only of its methods. Ways of attaining knowledge and the methods of research are oriented by the goals of research and by the formal nature of the truths of which we desire knowledge. The methods of theoretical economics and of the practical sciences of national economy cannot be the same (MENGER, 1985, p. 23-24).
\end{abstract}

Sob a influência da filosofia kantiana, pode-se depreender do pensamento weberiano, que o conhecimento não é capaz de captar a essência da realidade, mas apenas os fenômenos que nos são transmitidos através dos sentidos. Nega assim que o conhecimento possa reproduzir integralmente a realidade, tanto no sentido como na extensão. De acordo com Freund (1966, p.33), a oposição entre conceito e realidade encontra-se no fato de que, na concepção weberiana, o real é "infinito e inesgotável" e que, independentemente do método adotado, "cada um faz uma seleção na infinita diversidade da realidade empírica". Dessa forma, Weber rompe com dois princípios defendidos pelos historicistas, a saber, o da noção de realidade estruturada e o da possibilidade de obtenção de leis empíricas a partir dessa realidade. Na perspectiva historicista, eventos históricos e ações só adquirem significado a partir dessa realidade estruturada, ideia sistematicamente rejeitada pelo autor, que percebe

\footnotetext{
${ }^{5}$ Weber (1975).
} 
a realidade como um conjunto caótico de eventos aleatórios. Os tipos ideais são apenas um exemplo das suas várias tentativas de enquadrar essa realidade desestruturada.

Uma última questão da discussão metodológica weberiana é a da objetividade das Ciências Sociais, de onde o autor deriva a crítica ao romantismo historicista ${ }^{6}$ e deduz a questão da neutralidade axiológica. As convicções de Weber acerca da neutralidade axiológica das Ciências Sociais provocaram seu envolvimento direto em uma controvérsia com a Escola Histórica, que ficou conhecida como "Batalha dos Juízos de Valor" (Werturteilstreit), que teve início em 1909 durante uma reunião da Verrein für Sozialpolitik. De acordo com Swedberg (1998), Weber direcionou duras críticas a Schmoller e a todos que se opusessem à ideia de separação rigorosa entre análise científica e juízos de valor. Opondo-se ao posicionamento da Nova Escola Histórica ${ }^{7}$ (e particularmente ao posicionamento de Schmoller), que pregava a interferência dos julgamentos de valor ético no discurso científico, Weber defendia, acima de tudo, a neutralidade desse discurso, criticando aqueles que faziam passar por verdades científicas convicções pessoais.

Do exposto acima, deve-se considerar, contudo, que Weber não idealizava uma ciência livre da influência de valores, pois reconhecia a impossibilidade de delimitação do objeto de estudo isento dessas influências valorativas. Ainda assim, Weber (2001) não abandona a ideia da objetividade das Ciências Sociais e de que há verdades científicas que ultrapassam o julgamento subjetivo, afirmando ser possível reconhecer a validade de certo ordenamento conceitual independentemente da cultura.

\section{JOHN NEVILLE KEYNES E A BATALHA DOS MÉTODOS INGLESA}

Conforme observado anteriormente, a incidência de crises metodológicas constituiu um fenômeno de alcance internacional no final do século $\mathrm{XIX}^{8}$. No ambiente acadêmico inglês, essa crise encontrava-se diretamente relacionada à crescente desconfiança em relação à capacidade da ortodoxia corrente (diretamente influenciada pela tradição ricardiana, a essa altura já amplamente questionada) de oferecer tratamento a novas questões geradas por uma nova configuração institucional. Da mesma forma que no caso alemão, o ambiente intelectual encontrou-se polarizado, principalmente, entre correntes de tradição histórica e marginalista.

A corrente histórica inglesa, conforme exposto previamente, não constituiu uma escola de pensamento coesa (em contraste com a sua equivalente na Alemanha), uma vez que sua produção encontrava-se bastante dispersa e muitas vezes seus autores não compartilhavam dos mesmos paradigmas. A corrente de orientação marginalista, dessa forma, terminou por conduzir a academia britânica a uma nova ortodoxia. Fundamental nesse processo foram as publicações, em 1890, de Principles of Economics, de Alfred Marshall e The Scope and Method of Political Economy, de John Neville Keynes.

Como observado por Deane (1980), embora a chamada Revolução Marginal seja normalmente associada aos trabalhos de Jevons, Menger e Walras ${ }^{9}$, suas publicações não adquiriram força necessária para caracterizar uma revolução intelectual, uma vez que não houve a adesão imediata de um grupo mais amplo a uma nova ortodoxia. Diante desse fato, a autora afirma que a influência desses teóricos na

\footnotetext{
${ }^{6}$ Roscher e Knies e os problemas lógicos de economia política histórica, na metodologia.

${ }^{7}$ Fazem parte da Nova Escola Histórica autores como Werner Sombart (1863-1941) e Arthur August Caspar Spiethoff (1873-1957).

8 "Again, the so-called German doctrines, whatever may have been their origin, are no longer the peculiar possession of any one country. They are, for example, represented by a rising school of economists in the United States, who expressly repudiate the assertion that the new movement is exclusively a German movement. Even in England the spirit of the reaction was manifested long ago by Richard Jones, and in more recent years very forcible expression has been given to it by Cliffe Leslie and others" (KEYNES, 1999, p.16).

${ }^{9}$ Em especial Teoria da Economia Política, de Jevons, em 1871; Princípios de Economia, de Menger (1871); Elementos de Economia Pura, de Walras, em 1874.
} 
definição de novos campos e metodologia para a economia foi consideravelmente limitada, de forma que foram necessárias mais de duas décadas para que a aplicação da análise marginal conduzisse verdadeiramente a um novo paradigma. Observa-se, portanto, que esses três autores representam o início de uma mudança, ao passo que as obras de Marshall e Neville Keynes têm o papel definitivo de conferir legitimidade a essa mudança. Os Principles de Marshall assumiram a função de estabelecer os elementos de base da escola neoclássica inglesa e "possuíam a suprema vantagem de não pretenderem derrubar a ortodoxia clássica - mas simplesmente complementá-la e modernizá-la" (DEANE, 1980, p. 151); contavam, ainda, com uma maior simplicidade no tratamento matemático, o que permitiu maior alcance da obra. Não obstante, para contextualizar a publicação de Marshall, torna-se imperativo considerar a obra de Keynes que, ao dedicar-se aos elementos metodológicos da nova ortodoxia, conferiu-lhe maior legitimidade.

Baseando-se nas abordagens conciliatórias de Henry Sidgwick e Marshall, Keynes procurou, em The Scope and Method, unir a tradição ortodoxa com princípios defendidos pela Escola Histórica inglesa, buscando validar argumentos de ambos os lados da divisão conceitual. Essa intenção conciliatória como solução para a controvérsia metodológica foi explicitamente formulada pelo autor no prefácio do desse livro:

\begin{abstract}
At the same time, I have endeavoured to avoid the tone of a partisan, and have sought, in the treatment of disputed questions, to represent both sides without prejudice. Whilst making no attempt to bring about a complete reconciliation between opposing views, I have been able to shew that the nature of the opposition between them has sometimes been misunderstood, and its extent consequently exaggerated (KEYNES, 1999, p. 5).
\end{abstract}

É possível observar, contudo, que Keynes não conseguiu assumir uma postura imparcial, revelando uma clara preferência pela visão ortodoxa da economia. Dessa forma, apesar da manifesta intenção conciliatória, a real intenção de sua retórica consistia em preservar os princípios fundamentais da ortodoxia, relegando a abordagem histórica ao segundo plano. Conforme observado por Moore (2003), a formação inicial de Keynes foi caracterizada predominantemente pelo estudo de assuntos analíticos em detrimento de assuntos históricos ${ }^{10}$. Versado em lógica, apresentava uma afinidade natural com as diretrizes ortodoxas, dificultando a adoção de uma postura imparcial. Isto pode ser atestado na discussão que envolveu diretamente Cliffe Leslie (um dos maiores expoentes da Escola Histórica inglesa, junto com John Ingram) e Henry Sidgwick (defensor da abordagem ortodoxa e de quem Keynes havia sido discípulo), na qual Keynes posicionou-se claramente ao lado de Sidgwick e contra Leslie ${ }^{11}$.

Um dos principais pontos defendidos por Keynes em The Scope and Method é o da economia como ciência positiva. Após formular sua célebre divisão (economia positiva, economia normativa e a arte da economia), chega à conclusão de que a única abordagem verdadeiramente científica em economia envolveria a descoberta de fatos econômicos e suas uniformidades de maneira neutra, sem julgamentos éticos. $\mathrm{O}$ autor defende a ideia de que o estudo da economia deve reconhecer a influência de fatores morais em seu objeto sem, no entanto, discutir a validade objetiva desses valores. Em suas palavras, "political economy may recognize the operation of moral motives in the economic world, and yet not become an ethical science" (KEYNES, 1999, p. 26). Dessa forma, a economia, tomada como

\footnotetext{
10 "He initially studied mathematics at Cambridge (...). He subsequently transferred to the newly created Moral Science Tripos where, under the tutelage of Marshall, John Venn, and Sidgwick, he studied logic, psychology, moral philosophy, political philosophy, and economics" (MOORE, 2003, p. 9).

11 "The last meeting of our Moral Science Club for the year. We discussed Cliffe Leslie's article in this month's fortnightly. I agree with a good deal that he says, but his tone annoys me extremely. He misrepresents the views against which he is arguing, or at any rate he presents them in their most inadequate and imperfect form. His sole reference to Sidgwick's article on the Method of Political Economy is utterly unfair, and I think almost impertinent" (KEYNES apud, MOORE, 2003, p. 13).
} 
ciência positiva, deve ser independente da ética. Não se pode dizer o mesmo, contudo, do tratamento proposto à economia aplicada:

But it is a different matter when we turn to the applications of economic science to practice, that is, to applied economics, for no solution of a practical problem, relating to human conduct, can be regarded as complete, until its ethical aspects have been considered. It is clear, accordingly, that practical discussions of an economic character cannot be isolated from ethics (KEYNES, 1999, p. 32).

No que diz respeito ao método, Jon Neville Keynes posiciona-se inicialmente de forma moderada, afirmando que, da mesma forma que "if pure induction is inadequate, pure deduction is equally inadequate" (KEYNES, 1999, p. 81). Não obstante, seu discurso assume, progressivamente, um papel de defesa da supremacia do método dedutivo (com algumas concessões feitas por Keynes), isto porque considerava a abstração um meio indispensável para a compreensão de fenômenos complexos, bem como para o estabelecimento de relações de causalidade. Dessa forma, mesmo reconhecendo a distância que separa leis a priori da complexidade do mundo real, não considerava essas leis puramente fictícias uma vez que, de acordo com a sua reformulação do método dedutivo, tais leis tinham uma base de determinação real. Para Keynes (1999, p. 81-82), "it is from observation that even deductive economics obtains its ultimate premisses". Sua sistematização do método dedutivo é feita em três passos:

\begin{abstract}
The method in its complete form consists of three steps. It is necessary, first, to determine what are the principal forces in operation, and the laws in accordance with which they operate. Next comes the purely deductive stage, in which are inferred the consequences that will ensue from the operation of these forces under given conditions. Lastly, by a comparison of what has been inferred with what can be directly observed to occur, an opportunity is afforded for testing the correctness and practical adequacy of the two preceding steps, and for the suggestion of necessary qualifications. It will be observed that only one of these three steps - namely, the middle one - is strictly speaking deductive. (KEYNES, 1999, p. 100)
\end{abstract}

Observa-se de tal modo que a tática de Keynes para contrapor as acusações dos historicistas sobre a excessiva especulação do método dedutivo reside no reconhecimento do papel da observação. É a observação que irá garantir que as premissas não serão escolhidas arbitrariamente e que os resultados obtidos serão verificados e contrapostos com a realidade. Dessa forma, o autor reduz as objeções dos historicistas considerando-as uma série de mal-entendidos ${ }^{12}$. Todavia, embora Keynes (1999, p. 105) afirme que a economia política "must both begin with observation and end with observation", o papel relegado à fase dedutiva do método é de inegável supremacia. A função da observação torna-se, em consequência, meramente auxiliar à construção teórica e assume pouco valor prático no processo (tendo seu real valor, para Keynes, na justificativa dos procedimentos dedutivos).

Baseado em sua concepção metodológica, Neville Keynes propõe critérios de divisão do trabalho científico nas Ciências Sociais e dentro da própria economia. A principal divisão traçada diz respeito ao isolamento dessa última das demais Ciências Sociais. Sendo assim, embora Keynes reconhecesse a interdependência dos fenômenos sociais, para ele era mais indispensável a construção de um campo de conhecimento coeso que estivesse preocupado com fenômenos exclusivamente econômicos. Para o autor, "the recognition that the various forms of social activity are in many ways interdependent does not destroy the significance of the differences between them" (KEYNES, 1999, p.

12 "The true character of the deductive method is in particular misapprehended by those of its critics, who reject its aid in political economy on the ground that its employment means closing one's eyes to facts, and trying to think out the laws of the economic world in entire neglect of what is actually taking place" (KEYNES, 1999, p. 105). 
63). Os historicistas, por outro lado, defendiam uma concepção mais ampla de uma economia mais subserviente às Ciências Sociais ${ }^{13}$. Buscando solucionar a controvérsia - e lançando mão de uma hábil retórica conciliatória -, Keynes propõe a subdivisão da própria economia entre um ramo abstrato e um concreto (que iriam contemplar, respectivamente, etapas metodológicas dedutivas e indutivas). No entanto, conforme observado por Moore (2003), Keynes sutilmente mantém a superioridade do método abstrato afirmando que, mesmo no caso de economistas que se dedicassem à área concreta, seria necessário dominar previamente os princípios abstratos.

$\mathrm{Na}$ seção seguinte serão discutidas as contribuições de Weber e Keynes a partir da consideração de algumas questões específicas tratados por ambos, com a relação às disputas metodológicas correntes em sua época.

\section{DISPUTA E CONCILIAÇÃO METODOLÓGICA: J. NEVILLE KEYNES E MAX WEBER}

Ao contrapormos as soluções apresentadas por Neville Keynes e Max Weber para a Batalha dos Métodos, é possível observar a convergência de ambos em pontos fundamentais. Questões como a da neutralidade do discurso científico e da autonomia da economia teórica foram fundamentais para sancionar os novos paradigmas que definiram o estudo da economia no século XX. Todavia, apesar de ambos compartilharem concepções fundamentais, o tratamento metodológico pormenorizado dessas questões difere significativamente de um autor para o outro. Observa-se, portanto, que é justamente dos pontos de convergência que se podem derivar suas contribuições metodológicas mais interessantes. Alguns desses pontos serão abordados a seguir.

\subsection{INSTRUMENTOS DE ANÁLISE}

Com o intuito de promover um ordenamento conceitual para fins de pesquisa, Weber lança mão, conforme observado anteriormente, dos tipos ideais. $\mathrm{O}$ uso desses tipos como instrumento de análise encontra seu equivalente em teoria econômica no conceito de homem econômico - definido, entre outras coisas, como um indivíduo auto-interessado, racional e otimizador -, que proporcionou embasamento teórico para importantes desdobramentos da teoria econômica. Não obstante, ao contrapormos os tipos ideais weberianos com o homem econômico descrito por J. Neville Keynes, pode-se perceber diferenças de concepção significativas, particularmente no que tange à base empírica dessas construções.

Conforme mencionado na seção 2, Max Weber utiliza os tipos ideais com a intenção de enquadrar teoricamente uma realidade socioeconômica caótica. O objetivo dessa formulação reside, portanto, na atribuição de um maior rigor conceitual à análise de categorias sociais, permitindo um ordenamento abstrato dos fenômenos sociológicos. Todavia, "É impossível encontrar empiricamente na realidade este quadro, na sua pureza conceitual, pois trata-se de uma utopia" (WEBER, 2001, p. 138). Dessa forma, o autor deixa claro que os tipos ideais consistem em construções não empíricas que não devem ser confundidas com a realidade histórica. Sendo assim, a explicação sociológica fica condicionada ao contexto no qual o pesquisador está inserido, captando apenas alguns aspectos da realidade por ele percebida. O tipo ideal é construído, portanto, a partir de uma "acentuação unilateral de um ou de vários pontos de vista" (WEBER, 2001, p. 137), formando um quadro de pensamento homogêneo. Ao promover um afastamento da realidade, os tipos ideais permitem, simultaneamente, uma aproximação da mesma por meio de um maior rigor analítico.

\footnotetext{
13 "The Comteam historicists, such as Ingram, argued that economics should be completely subsumed under the umbrella of sociology, while all other historicists demanded that the discipline should at least have a broader scope" (MOORE, 2003, p. 26).
} 
O homem econômico definido por Keynes, apesar de representar uma construção conceitual típico-ideal, não se encaixa nos termos definidos por Weber. Sua definição baseia-se na premissa do comportamento guiado pelo auto-interesse, significando, no aspecto econômico, "the attainment of a maximum of wealth with a minimum of effort and sacrifice" (KEYNES, 1999, p. 60). Baseando-se na argumentação de que os fenômenos investigados pela Ciência Econômica devem ser precedidos e seguidos por observação, o autor critica a concepção do homem econômico de Mill, afirmando que seu erro "is that of mistaking a part for the whole, and imagining political economy to end as well as begin with mere abstractions" (KEYNES, 1999, p. 57). É nesse ponto que a concepção do instrumento analítico de Keynes difere em maior grau da concepção do tipo ideal weberiano, uma vez que esse último não possui base empírica verificável. $\mathrm{O}$ homem econômico keynesiano surge, por outro lado, como uma abstração do homem real, pois, de acordo com o autor, os postulados que o definem são predominantes nas relações econômicas do mundo real:

Still the desire for wealth is, under normal conditions, the active impelling force; (...) It is this fact of common experience that justifies economists in starting from the conception of the economic man, as approximately typical of actual men considered in their economic relations. Conclusions based on this conception contain a hypothetical element; but they are nevertheless, at any rate in certain departments of the science, within measurable distance of the concrete realities of the actual economic world (KEYNES, 1999, p. 60)

Nesse sentido, Neville Keynes chega a afirmar que o homem econômico existiria próximo à sua forma pura em algumas situações concretas ${ }^{14}$.

\subsection{OBJETO DE ESTUDO}

Em seu livro, John Neville Keynes defende uma postura isolacionista no que diz respeito à delimitação do objeto de estudo da Ciência Econômica. Ao rejeitar as proposições de Comte e Mill, seu discurso assume um tom mais moderado, qualificando seu isolacionismo de maneira singular. A posição de Comte de que o campo de estudo da economia deveria ser submetido ao campo mais amplo das Ciências Sociais é categoricamente refutada pelo autor, afirmando que essa visão "overlooks the fact that only by specialization within proper limits can scientific thoroughness and exactness be attained in any department of knowledge" (KEYNES, 1999, p. 55-56). Da mesma forma, a posição isolacionista extremada de Mill, na qual o objeto de estudo da economia deveria ater-se exclusivamente às investigações teóricas abstratas, também é rejeitada. Não obstante, conforme observado por Moore (2003), apesar da retórica conciliatória, Neville Keynes não rejeita, mas apenas qualifica a posição isolacionista de Mill, incorporando a investigação da economia aplicada (concreta) ao objeto de estudo. Dessa forma, mantém a pesquisa abstrata como objeto central e relega os assuntos de economia aplicada ao segundo plano.

Keynes via como necessária, portanto, uma divisão do trabalho acadêmico que estabelecesse um departamento distinto de investigação econômica. A predominância motivacional da busca pela riqueza nas relações econômicas em detrimento de outros objetivos é uma das razões que garantiria legitimidade ao recorte investigativo proposto. Sendo assim, apesar de reconhecer a interdependência dos fenômenos sociais e a importância de estudar o mundo real, o campo da Ciência Econômica não perde, na visão do autor, sua individualidade:

\footnotetext{
14 "As a matter of fact, this approximation is cases a very near approximation indeed. In dealing, for instance, with prices on the Stock Exchange, or in the great wholesale markets, under modern industrial conditions, we are for the most part concerned with the economic activities of persons who practically realise in actual life the notion of the economic man" (KEYNES, 1999, p. 58).
} 
Since a realistic treatment of economic problems is usually essential to their complete solution, it is necessary that economists should keep in view all the various aspects of social life; and it is clearly mischievous to aim at an entire isolation of economics from other social sciences. But political economy does not, therefore, lose its individuality. For the recognition that the various forms of social activity are in many ways interdependent does not destroy the significance of the diferences between them; and to do away with the boundaries, that now separate the different social sciences, would be to sacrifice all the gain resulting from scientific division of labour (KEYNES, 1999, p. 63).

Em contraste com a posição de Keynes, Weber propõe uma concepção mais ampla do objeto de estudo da Ciência Econômica, conferindo maior importância à intersecção dos campos da sociologia e da economia. Dessa forma, o autor idealizou um projeto de Ciência Socioeconômica (Sozialökonomik), no qual seriam contemplados não apenas o estudo da teoria econômica abstrata, como também da história econômica e da sociologia econômica. No caso específico da disciplina da sociologia econômica, Weber buscou "integrar, numa única análise, a ideia do comportamento movido por interesse com a ideia do comportamento social” (SWEDBERG, 2005, p. 13). Tal análise é construída a partir da fusão dos conceitos de ação econômica e ação social:

\begin{abstract}
A seu ver, a teoria econômica analisa situações em que o agente é movido principalmente pelos interesses materiais e tem a utilidade como objetivo, mas não leva em conta o comportamento de outros atores (ação econômica). A sociologia considera tanto a ação movida pelos interesses ideais quanto pelos interesses materiais que também é orientada pelo comportamento dos outros (ação social). A sociologia econômica enfoca a ação social econômica - isto é, a ação movida principalmente pelos interesses materiais, que é voltada para a utilidade $e$ leva outros agentes em conta (SWEDBERG, 2005, p. 48).
\end{abstract}

Cabe destacar, contudo, que a intenção de Weber ao propor a ampliação do objeto da economia não era a de substituir a teoria econômica abstrata como propunham os historicistas. Pelo contrário, uma vez que o autor demonstrava plena confiança na capacidade explicativa da teoria para a compreensão dos fenômenos econômicos. Não obstante, diferentemente de Keynes, não é estabelecida uma hierarquia entre o campo teórico e o aplicado da economia, de forma que a teoria econômica, a história econômica e a sociologia econômica complementar-se-iam mutuamente e com capacidades explicativas equivalentes.

\title{
4.3. QUESTÕES DE MÉTODO
}

Ao rejeitar os pressupostos de Windelband e Rickert, que propunham a classificação das ciências com base no tipo de método utilizado, Weber propõe o pluralismo metodológico como alternativa viável. Sua concepção parte do princípio de que não há um método exclusivo para cada ciência, de forma que uma mesma ciência pode recorrer a mais de um método de acordo com as circunstâncias. Baseando-se na premissa da impossibilidade de apreensão integral da realidade, tanto o método generalizante quanto o individualizante representam, para o autor, diferentes tipos de afastamento da realidade para fins de construção conceitual.

Da mesma forma que Weber, Keynes também defende o pluralismo metodológico, reconhecendo espaço tanto para o método dedutivo quanto para o indutivo na pesquisa em economia. Ao descrever o método dedutivo em suas três etapas, o autor afirma que este não se dá de maneira plena sem o auxílio da indução:

It will be observed that only one of these three steps-namely, the middle one - is strictly speaking deductive. The so-called deductive method in its complete form is thus seen to be not an exclusively deductive method. It may more accurately be described as a 
method which, whilst predominantly deductive, is still aided and controlled by induction (KEYNES, 1999, p. 100).

Keynes (1999) destaca três principais funções da observação no método dedutivo: guiar o economista na sua escolha original de premissas, possibilitar ao economista determinar a proximidade de suas premissas com os fatos reais e, por último, como um recurso para testar suas inferências dedutivas. Todavia, observa-se que, diferentemente de Weber, o autor estabelece um clara hierarquia metodológica, conferindo um papel meramente auxiliar à indução e à observação, sustentando que "a teoria dedutiva e a economia positiva objetiva constituíam o núcleo e o centro da disciplina científica da economia" (DEANE, 1980, p. 141). Nas palavras de Keynes (1999, p. 107), "observation determines the limits of the positive validity of laws deductively obtained".

\subsection{NEUTRALIDADE CIENTÍFICA}

Posicionando-se contrariamente à posição dos historicistas ingleses, que julgavam possível a construção de uma ciência ética, Keynes (1999, p. 22) propõe uma concepção de economia como ciência positiva, "which is concerned purely with what is, and which seeks to determine economic laws". Na visão do autor, a Ciência Econômica deveria evitar a construção de percepções éticas e julgamentos de valor. O caráter distinto dessa ciência consiste, particularmente, em inquerir sobre "o que é" e não sobre "o que deveria ser":

(...) it is rather the failure to recognize the fundamentally distinct character of enquiries into what is, and enquiries into what ought to be, that is really responsible for attempts to solve practical economic questions without reference to their ethical aspects (KEYNES, 1999, p. 24).

Ainda assim, Keynes não nega que, em sua concepção da Ciência Econômica, motivos morais possam ser levados em consideração. Não obstante, isso não impossibilita estudar os fenômenos econômicos positivamente, uma vez que o autor estabelece claramente a diferença entre reconhecer a influência de motivos morais, de um lado, e discutir a validade desses motivos, de outro. Nas suas palavras:

To recognise the influence, act, al or potential, exerted by the economic ideals that men may frame for themselves is not the same thing as to discuss the objective validity of those ideals; and our treatment of economic science may remain strictly positive (in the sense in which we are now using that term), while at the same time we enquire in detail in what ways economic phenomena are or may be affected by the pressure of public opinion, or by motives of justice, and kindliness, and concern for the general well-being (KEYNES, 1999, p. 25).

Da mesma forma que Keynes, o autor alemão se opõe à ideia de ciência moral defendida pelos historicistas alemães e prega uma visão de ciência neutra. No entanto, apesar de defender com rigor o princípio da neutralidade axiológica, reconhece a relação valorativa como um critério de seleção inseparável das Ciências Sociais:

Por certo que, sem as ideias de valor do investigador, não existiria nenhum principio de seleção, nem o conhecimento sensato do real singular, da mesma forma como sem a crença do pesquisador na significação de um conteúdo cultural qualquer, resultaria completamente desprovido de sentido todo o estudo do conhecimento da realidade individual, pois também a orientação da sua convicção pessoal e a difração de valores no espelho da sua alma conferem ao seu trabalho uma direção (WEBER, 2001, p. 132). 
Observa-se, contudo, que mesmo classificando o ponto de partida da investigação científica como altamente subjetivo, o autor estabelece essa seleção inicial apenas como uma estrutura limitante da investigação científica objetiva que a sucede. Dessa forma, apesar de admitir uma seleção valorativa, Weber não abre mão da objetividade investigativa e da neutralidade do discurso científico. Em suma, conforme observado por Freund (1966, p. 44), a seleção "é o momento subjetivo que torna possível um conhecimento objetivo limitado, desde que o sábio tenha consciência dessa limitação inevitável".

\title{
4.5. A DIVISÃO DO TRABALHO ACADÊMICO EM CIÊNCIAS SOCIAIS
}

As tradições teóricas que incorporaram as contribuições de Weber e N. Keynes tiveram influência direta na divisão do trabalho acadêmico nas Ciências Sociais durante o século XX. Essa se expressa mais claramente na divisão definida por Velthuis (1999, p. 16) como "Robbins/Parsons division of labor". De acordo com o autor, Talcott Parsons, ao incorporar a conhecida definição de economia de Lionel Robbins ${ }^{15}$, buscou estabelecer uma delimitação do campo de estudo da sociologia em termos similares.

Parsons define a sociologia a partir de uma perspectiva analítica do comportamento humano, com a exclusividade do aspecto sociológico consistindo no conteúdo valorativo atribuído ao comportamento, de maneira que "if economics was to study the allocation of means in the means-ends chain that constitutes human behavior, sociology would concentrate on the "value factor"' (VELTHUIS, 1999, p. 5). Entende-se, portanto, que a divisão do trabalho, nos termos estabelecidos por Robbins e Parsons, legitimou o isolacionismo disciplinar (particularmente entre economia e sociologia) observado a partir da década de 1930:

\begin{abstract}
With hindsight, we have to conclude that as a result of Parson's quest for an independent sociology, economics did become unrelated to sociology. It could simply ignore the institutional context or the value-factor of economic action, since they were the domain of sociology, not economics, according to the Robbins/Parsons division of labor (VELTHUIS, 1999, p. 16).
\end{abstract}

Parsons realizou considerável parte de seus estudos na Universidade de Heidelberg, de onde recebeu significativa influencia das ideias de Max Weber. Particularmente, a sociologia econômica de Parsons possui fortes pontos de equivalência com a sociologia econômica weberiana. De acordo com Velthuis (1999, p. 14), para Parsons ${ }^{16}$, ambos “... Weber and Durkheim recognized that mainstream economics merely needed to be complemented and not substituted with an institutional analysis".

Da mesma forma, embora Robbins (1945) tenha contestado a definição marshalliana de economia, identificava-se com a mesma tradição teórica defendida por John Neville Keynes. Em um contexto de divergência metodológica, dessa vez envolvendo os institucionalistas americanos (Veblen, Mitchel e Commons, principalmente) como representantes da nova heterodoxia ${ }^{17}$, o autor publica $A n$ Essay on the Nature and Significance of Economic Science, em 1932. Seu objetivo com esse livro é reafirmar a posição da escola neoclássica inglesa, conforme exposta anteriormente por Neville Keynes. O principal, segundo Deane (1980, p. 189) é que a tese de ser "a Economia uma disciplina científica apoiava-se exclusivamente em seus aspectos positivos, de que a principal realização dos economistas foi um sistema de análise abstrata que se baseava na inferência lógica a partir de postulados simples e susceptível de aplicabilidade universal”. Robbins (1945, p. 91) também recorre ao pensamento

\footnotetext{
15 "Economics is the Science which studies human behaviour as a relationship between ends and scarce means which have alternative uses" (ROBBINS, 1945, p. 31).

16 "Granovetter suggests that Weber and Durkheim, just like Parsons, reinforced the Robbins/Parsons division of labor that led to the neglect of sociology by mainstream economics" (VELTHUIS, 1999, p. 14).

${ }^{17} \mathrm{O}$ institucionalismo desenvolveu-se especialmente entre as décadas de 1920 e 1930, alcançando grande espaço no pensamento econômico norte-americano.
} 
weberiano para sustentar sua visão do relacionamento entre economia e ética, chegando a afirmar que a "economic analysis is wertfrei ${ }^{18}$ in the Weber sense".

Cabe destacar, contudo, que a influência exercida pelas obras de Weber e N. Keynes transcende a questão abordada acima, assumindo diferentes significações e permeando as obras de autores das mais variadas tradições de pensamento durante o século XX. Schumpeter que foi um dos mais influentes economistas do seu tempo, ocupando o cargo de presidente da Sociedade de Econometria e da Associação Americana de Economistas, baseou-se em Weber não apenas em seus primeiros escritos, mas especialmente no que diz respeito à proposta de divisão da Ciência Econômica em quatro domínios distintos: história econômica, estatística, teoria e sociologia econômica. E, assim como Weber, idealizava um modelo de Ciência Econômica no qual uma abordagem não dominasse indevidamente as demais:

Que Schumpeter concordava em linhas gerais com a posição de Weber no Methodenstreit de que a abordagem histórico-empírica de Schmoller era tão necessária quanto a abordagem histórico-analítica de Menger fica claro em sua avaliação da batalha dos métodos. Na verdade, toda a teoria de Schumpeter sobre o nascimento da teoria econômica parece ter sido concebida para fazer justiça aos diferentes ramos dos estudos econômicos (SWEDBERG, 2005, p. 284).

No entanto, o ponto de maior identificação nas obras dos dois autores não está no reconhecimento da autonomia dos domínios, mas no reconhecimento de sua complementaridade. É com esse objetivo que Schumpeter estabelece o domínio da sociologia econômica, buscando integrar a análise histórica e institucional à teorização. É na conciliação formal da tradicional oposição entre teoria e história que a influência de Weber adquire maior visibilidade.

Deve-se reconhecer finalmente a influência de Neville Keynes na obra de Marshall (e não apenas a de Marshall em Keynes) ao se avaliar o alcance de sua exposição metodológica. Keynes não apenas legitimou indiretamente a publicação dos Princípios, como também teve papel direto na sua elaboração, tendo comentado e contribuído para a elaboração da obra ativamente antes de sua publicação ${ }^{19}$ (da mesma forma que Marshall contribui para Scope and Method). A importância disso é que decorrem da obra de Marshall as principais sugestões, ou indicações de progresso da economia nos anos subsequentes à da publicação do seu livro. Conforme atesta Schumpeter (1970, p.107), “A literatura econômica nos trinta anos decorridos desde 1890, abunda com o desenvolvimento, as reformulações e os corolários de proposições e aspectos da técnica marshalliana”.

\section{CONCLUSÃO}

As controvérsias metodológicas que dominaram o final do século XIX e início do século XX representaram um importante momento de transição na história do pensamento econômico. Tanto no ambiente acadêmico alemão como no ambiente acadêmico anglo-saxão. Neste momento, vertentes de orientação histórica contestaram a utilidade da análise teórico-abstrata (bem como o viés que acompanhava essa análise) para o desenvolvimento de uma Economia científica. Mais do que uma oposição entre história e teoria, a Batalha dos Métodos terminou por definir o próprio lugar da Ciência Econômica entre as demais Ciências Sociais.

Em retrospecto, a análise dessas disputas nos permite observar que, no longo prazo, o grande "vencedor" foi o marginalismo, responsável pela redefinição dos problemas da nova ortodoxia

\footnotetext{
${ }^{18}$ Livre de valores, em tradução aproximada.

19 "Marshall made numerous comments on successive drafts of the methodological tract (as Keynes, in turn, commented on successive drafts of Marshall's long awaited Principles over the same period) (...)" (MOORE, 2003, p. 14).
} 
econômica neoclássica que se estabeleceu progressivamente no primeiro quarto do século XX. Com o auxílio de instrumentos analíticos de fácil e variada aplicação, essa vertente proporcionou à economia uma aparente neutralidade científica. Ao consolidar uma precisão quantitativa superior aos sistemas concorrentes, a Escola Marginalista tornou-se responsável por dotar de prestígio e credibilidade a produção acadêmica da Ciência Econômica.

Não obstante, algumas décadas separam a publicação das primeiras obras marginalistas e a consolidação da escola neoclássica como principal corrente de pensamento econômico no século XX. Relevantes para isso foram os posicionamentos de Max Weber e John Neville Keynes em relação às disputas metodológicas deste período. Dessa forma, as análises desses dois autores no contexto da Batalha dos Métodos revelam importantes pontos de concordância com o encaminhamento geral ao qual a economia tomou nas décadas subsequentes. Observa-se, em adição, que esses pontos recebem tratamentos diferenciados e apontam para desdobramentos distintos em cada um.

Embora ambos desenvolvam instrumentos de análise conceitual baseados em "tipos", o tipo ideal weberiano não compartilha da base empírica do "homem econômico" de Keynes. Da mesma forma, ainda que os dois autores defendam alguma espécie de isolacionismo da análise teórica da economia, essa defesa se dá de maneira mais radical em Keynes, sendo compensada em Weber pela elaboração da Sozialökonomik. Em relação ao método, embora ambos defendam alguma espécie de pluralismo metodológico, Keynes sustenta a supremacia da análise dedutiva, ao passo que Weber não estabelece uma relação hierárquica entre os métodos.

Por fim, com relação à neutralidade axiológica do discurso científico, tanto para Neville Keynes quanto Weber, a Economia é vista como ciência positiva independente da Ética, ainda que o segundo reconhecesse bem mais as influências valorativas na delimitação do objeto.

Dessa forma, ao comparar-se o posicionamento desses autores no que diz respeito às disputas metodológicas do final do século XIX, observa-se que o posicionamento de Weber se estrutura como uma espécie de versão qualificada do pensamento nevilliano. Sendo assim, ao mesmo tempo em que Weber partilha de boa parte das premissas ortodoxas expostas por Neville Keynes, o tratamento dado pelo autor a essas questões desenvolve-se em uma concepção metodológica menos rígida, capaz de combinar em uma mesma análise aspectos teóricos, históricos e institucionais sem, no entanto, abandonar a autonomia analítica oferecida por essas disciplinas. Por isso, Weber é mais relevante no contexto atual, de reavaliação das tradicionais fronteiras (fundadas a partir da Batalha dos Métodos) que separam as Ciências Sociais.

ABSTRACT: By the late nineteenth century and early twentieth century, economics was moving towards becoming an autonomous science amid a wider theoretical dispute, in which the abstract/deductive and the historical/inductive methods were opposed. Among the proposed solutions to reconcile both perspectives, stand out those of John Neville Keynes in England and Max Weber in Germany. The present work aims to analyze and counteract the propositions stated by both authors concerning the methodological dispute. The main hypothesis is that Keynes' and Weber's points of view would have sanctioned the further course of Economics by admitting separate but complementary places to history and economic theory within the history of economic though.

Keywords: Max Weber; Neville Keynes; Methodenstreit; Social Sciences.

\section{REFERÊNCIAS}

BRUE, Stanley L. História do Pensamento Econômico. São Paulo: Pioneira-Thompson, 2005.

DEANE, Phyllis. A Evolução das Idéias Econômicas. Rio de Janeiro: Zahar, 1980.

FEIJÓ, Ricardo. Economia e Filosofia na Escola Austríaca: Menger, Mises e Hayek. São Paulo: 
Livraria Nobel, 2000.

FREUND, J. Sociologia de Max Weber. Rio de Janeiro: Forense-Universitária, 1966.

HAYEK, Fredrich. The Fortunes of Liberalism: Essays on Austrian Economics and the Ideal of Freedom. University of Chicago Press, 1992.

HUNT, E. K. História do Pensamento Econômico. Rio de Janeiro: Campus, 2005.

KEYNES, John Neville (1891). The Scope and Method of Political Economy. Kitchener: Batoche Books, 1999.

MENGER, Karl. (1883). Investigations into the Method of the Social Sciences with Special Reference to Economics. New York-London: New York Press, 1985.

MOORE. John Neville Keynes's Solution to the English Methodenstreit. Journal of the History of Economic Thought: Volume 25 / Issue 01 / March 2003, pp 5 - 38.

ROBBINS, Lionel. (1935). An Essay on the Nature and Significance of Economic Science. Second Edition, Revised And Extended. London: Macmillan and co. Limited, 1945.

SCHUMPETER, Joseph. (1954). A História da Análise Econômica. Livro 1. Rio de Janeiro: Fundo de Cultura, 1964.

Teorias Econômicas: de Marx a Keynes. Rio de Janeiro: Zahar, 1970.

SWEDBERG, Richard. Max Weber as an Economist and as a Sociologist: Towards a Fuller Understanding of Weber's View of Economics. American Journal of Economics and Sociology, New York, 1999.

. Max Weber e a Ideia de Sociologia Econômica. Rio de Janeiro: UFRJ; São Paulo: Beca Produções Culturais, 2005. (Coleção Economia e Sociedade).

WEBER, Max. (1922). Marginal Utility Theory and the Fundamental Law of Psychophysics. Social Science Quarterly, 56 (1975): 32.

(1917). Ciência e Política - Duas Vocações. São Paulo: Cultrix, 2000.

(1922). Metodologia das Ciências Sociais. Campinas: Editora Cortez-Unicamp, $4^{\mathrm{a}}$ edição,

Parte 1 e $3^{\text {a }}$ edição, Parte 2, 2001.

VELTHUIS, O. The changing relationship between economic sociology and institutional economics: from Talcott Parsons to Mark Granovetter. The American Journal of Economics and Sociology, New York, v. 58, n. 4, p. 629-649, oct., 1999. 